\title{
Tecnologia, Inovação e Educação: Caminhando Juntas para o Desenvolvimento de Smart Cities
}

\author{
Marcelly Homem Coelho - UFSC - marcellyhc@gmail.com \\ Morgana Sartor - UFSC - morgana.sartor@gmail.com \\ Maitê Thomazi Manenti - UFSC - maite.manenti@gmail.com \\ Luciana Bolan Frigo - UFSC - luciana.frigo@ufsc.com.br \\ Eliane Pozzebon - UFSC - eliane.pozzebon@ufsc.com.br
}

\begin{abstract}
The present work aims to socialize the contributions of innovations applications and their interdisciplinarities for the construction of an intelligent city prototype using IoT concepts and its applications, in order to search for a variety of methods of teaching technology, computing and electronics. The workshops were attended by High School students. Since the members' reports and discussions with the group, it was possible to perceive that the activities aroused their interest, stimulated creativity, group work and logical reasoning, which gave the students a glimpse of the relationship among the new knowledge accomplished and the subjects which they face everyday.
\end{abstract}

Resumo. O presente trabalho visa socializar as contribuições de aplicações inovadoras e de suas interdisciplinaridades para a construção de um protótipo de cidade inteligente utilizando conceitos e aplicações de IoT, com o objetivo de buscar métodos variados para o ensino de tecnologia, computação e eletrônica. A oficina teve como participantes estudantes do Ensino Médio. A partir dos relatos dos integrantes e discussões com o grupo, foi possível perceber que as atividades lhes despertaram o interesse, estimularam a criatividade, o trabalho em grupo e o raciocínio lógico, oportunizando aos estudantes vislumbrarem as relações existentes entre os novos conhecimentos adquiridos e os assuntos com os quais se deparam no cotidiano.

\section{Introdução}

O termo Smart Cities - ou cidades inteligentes - refere-se à aplicação de Tecnologias de Informação e Comunicação (TIC) como ferramenta para melhorar a resolução de problemas envolvendo questões sociais como infraestrutura e serviços das cidades (GAMA et al., 2012). Assim, contribuindo para um mundo melhor onde todos têm a oportunidade de se beneficiar das modernizações.

O conceito também é visto (PEREIRA, 2016) como um conjunto de recursos e negócios inovadores que visam criar soluções que promovam a inclusão, sustentabilidade e a integração social, fatores que contribuem para o avanço na qualidade de vida de toda a sociedade. 
É importante destacar a não existência de setores da sociedade, seja ela urbana ou rural, que atualmente não estejam interligados de alguma forma com a tecnologia. De acordo com (ANDERLE at al., 2013), os conceitos de cidades inteligentes e Internet das Coisas (IoT) estão presentes nas empresas, instituições de ensino, sistemas de transporte, rede elétrica, monitoramento ambiental, controle agrícola e entre outras áreas.

Conforme é exposto pelos autores (COELHO et al., 2016), é de suma importância buscar alternativas para proporcionar o processo de ensino-aprendizagem mais interdisciplinar, dinâmico e atraente transformando assim, a atividade de busca do conhecimento, em novos ambientes, motivadora para estudantes do Ensino Médio.

Diante do contexto das aplicações de inovações em cidades inteligentes e tratando das suas interdisciplinaridades, relacionadas principalmente, à tecnologia e à necessidade de buscar métodos variados para o ensino das ciências exatas surge a proposta do Projeto Meninas Digitais - UFSC de acadêmicos de Engenharia e Tecnologia de Informação, juntamente com estudantes do Ensino Médio da Escola de Educação Básica de Araranguá, construírem e implementarem um protótipo de cidade inteligente utilizando conceitos e aplicações de IoT.

Este artigo conta, além desta parte introdutória, com uma segunda seção onde são apresentados fundamentos teóricos sobre o tema da tecnologia como ferramenta educacional interativa no ensino. Na seção 3 são citadas aplicações tecnológicas em cidades inteligentes; na seção 4 são descritos os objetivos e demais informações do projeto de extensão universitária; na seção 5 são apresentadas as metodologias e ferramentas computacionais aplicadas na oficina; a seção 6 relata os resultados obtidos; e a última seção, 7, descreve as considerações finais.

\section{Tecnologia como Ferramenta Interativa no Ensino}

De acordo com (VALENTE, 2008), para incentivar o aprendizado de estudantes é de extrema importância buscar alternativas para proporcionar um processo de ensinoaprendizagem atraente juntamente com um ambiente motivador. $\mathrm{O}$ artigo relata a experiência de oficinas práticas, as quais tratam do uso do computador e demais ferramentas tecnológicas educacionais que visam melhorar o processo de ensino e construção de novas habilidades e competências. Abaixo são apresentadas algumas iniciativas relacionadas ao assunto.

A proposta criada pelos autores (CARVALHO et al., 2013) para a área de TIC foi executar um projeto de inclusão digital que fornecesse, aos estudantes de Ensino Médio de escolas estaduais de Minas Gerais, novos conhecimentos, pensamentos computacionais e habilidades envolvendo o uso da tecnologia no ensino tradicional. $\mathrm{O}$ projeto é conhecido como Reinventando o Ensino Médio - REM - e busca consolidar o ensino por meio da adição de novos conteúdos de áreas de empregabilidade específicas, como por exemplo: Tecnologias da Informação, Comunicação Aplicada, Turismo, Meio Ambiente, Recursos Naturais, Empreendedorismo, Cidades Inteligentes entre outros. Desse modo, além do estudante ter acesso aos conteúdos básicos, a instituição de ensino também oferecerá disciplinas específicas, ampliando assim o currículo e contribuindo para o desenvolvimento cognitivo. 
Em busca de enriquecer o envolvimento de crianças no processo de criar e contar histórias, (POSADA et al., 2014), apresentam investigações sobre como associar tecnologias de interação aos processos educativos envolvidos na construção de histórias de maneira colaborativa, inclusiva e engajadora. Para tanto, foi realizado um estudo exploratório com crianças de uma escola da rede municipal de ensino de Campinas para analisar e viabilizar a operacionalização da inserção de laptops na escola. Foram realizadas, como uma das metodologias de pesquisa, oficinas com o objetivo de articular soluções para os problemas encontrados durante a utilização dos laptops no cotidiano dos principais envolvidos. O objetivo da atividade foi realizar uma primeira aproximação entre a comunidade escolar e as interfaces tangíveis e narrativas.

A fim de melhorar a dinâmica de ensino-aprendizagem dos estudantes em sala de aula, os autores (FERREIRA et al., 2015) descrevem uma proposta de desenvolvimento de um módulo de software para gamificação de Ambientes Educacionais Ubíquos espaços físicos equipados com recursos computacionais (sensores, lousas eletrônicas, câmeras, microfones, entre outros) - com o potencial de incorporar a visão de computação ubíqua. Para isso, foi utilizada a plataforma multimídia para capturar aulas Classroom eXperience, que gera documentos de hipermídia em diferentes formatos de apresentação, e de elemento de jogos, como pontuação, rankings e conquista de medalhas, para promover a motivação e o envolvimento dos estudantes.

Os autores (OLIVEIRA e ARAÚJO, 2016) ressaltam o uso da robótica educacional para estimular estudantes a utilizar do pensamento computacional, que pode ser entendido como uma abordagem de resolução de problemas e compreensão do comportamento humano norteado por conceitos fundamentais da Ciência da Computação, utilizando da robótica educativa como mediadora. Para tal fim, foi planejada uma oficina para desenvolver as habilidades do pensamento computacional que podem ser estimuladas por meio da construção e implementação de robôs.

Segundo (SILVA et al., 2016) o uso da tecnologia se apresenta como uma opção aos diferentes métodos de aprendizagem e avaliação em diferentes níveis de ensino. $\mathrm{O}$ propósito do trabalho é promover o rompimento de paradigmas, pois, por meio da metodologia do processo de aprendizagem em ambientes digitais será possível que os estudantes passem a utilizar diferentes formas de interação, vencendo empecilhos referentes ao tempo e ao espaço, ampliar processos de relacionamentos e a conscientização, e ainda valorizar o sujeito como construtor da sua aprendizagem. Para este fim, a metodologia de processo de avaliação foi aplicada no contexto da disciplina Projetos de Aprendizagem em Ambientes Digitais, oferecida em caráter eletivo para acadêmicos de diferentes Cursos de Licenciatura pela Faculdade de Educação da Universidade Federal do Rio Grande do Sul.

O trabalho apresentado pelos autores (FERNANDEZ, et al., 2015) descreve a realização de oficinas que utilizam IoT no contexto de aprendizagem baseada em projetos para a implementação de uma casa inteligente. De acordo com os autores, a identificação do problema, a tomada de consciência a respeito de suas causas, e a busca de soluções tecnológicas de forma a incentivar o aprendizado dos estudantes, são aspectos importantes a serem levados em consideração na elaboração de atividades relacionadas ao ensino de programação e de robótica. As aplicações - em uma casa inteligente - permitiram aos participantes adquirirem conhecimentos sobre conceitos 
básicos de eletrônica e IoT, descobrirem possibilidades de utilização de sensores e atuadores, realizarem a comunicação de dados via Bluetooth, além de, possibilitar uma melhor interação durante a execução das tarefas e apresentações dos protótipos finais.

\section{Aplicações Tecnológicas no Desenvolvimento de Cidades Inteligentes}

Existem diversas aplicações tecnológicas no contexto de cidades inteligentes buscando sempre potencializar soluções integradas para beneficiar a sociedade. Para isso Engenharia e a Tecnologia de Informação estão sendo interligadas, usando princípios e técnicas de Internet das Coisas, computações em nuvem, redes de sensores sem fio, inteligência artificial, sistemas de informação geográfica e entre outras. Alguns exemplos de aplicações são descritos a seguir.

O campo que pode melhorar com o uso da tecnologia é a segurança. Acidentes graves, desastres ambientais e ataques terroristas trazem grandes problemas e desafios para a segurança pública. Uma análise dos diferentes tipos de dados urbanos permitiria aprender com dados históricos e possivelmente prever situações de emergência. Detecção de desastre ambiental, como deslizamentos de terra, rompimento de represas, acidentes nucleares, poderiam favorecer a evacuação da população. $\mathrm{O}$ entendimento e a prática deste tipo de situação são de extrema importância para o planejamento efetivo de socorro humanitário, administração das consequências do desastre e reconstrução das cidades.

A ciência e a tecnologia podem trazer melhorias para as áreas médicas, ajudando a facilitar o trabalho dos profissionais da saúde, nos diagnósticos, tratamentos de doenças, resultados de exames, tempo de recuperação, identificação de alterações nos genes e entre outros. Disponibilizando assim, informações adicionais e precisas que podem facilitar a tomada de decisões de especialistas de diversas áreas da saúde, conforme (ROCHA e CASTIGLIONI, 2005).

A combinação da inovação e práticas pedagógicas no ensino aprendizagem tem papel fundamental na buscar de novas alternativas para proporcionar o ensino dos conteúdos tradicionais mais atraentes. $\mathrm{O}$ uso de ferramentas tecnológicas pode permitir o desenvolvimento de novas possibilidades para os estudantes, como experimentação, realização de práticas sobre assuntos teóricos e entre outros benefícios. Despertando assim a criatividade e habilidade para todas as pessoas envolvidas no processo de busca pelo conhecimento.

\section{Sobre o Projeto Meninas Digitais - UFSC e suas Práticas}

O projeto Meninas Digitais - UFSC faz parte de um Programa da Sociedade Brasileira da Computação (SBC) tem como objetivo divulgar a área de Ciência da Computação para despertar o interesse de estudantes do ensino médio/tecnológico, a conhecerem melhor a área e, desta forma, motivá-los a seguir carreira afins.

As ações do projeto são diversificadas: são promovidos minicursos e oficinas; realização de dinâmicas; palestras com estudantes e profissionais que já atuam na área compartilhando suas experiências, visitas técnicas a universidades e empresas de tecnologia e entre outras. 
Estudantes de escolas públicas da região são convidados a participar de atividades práticas que privilegiam as seguintes ações: discussão, projeto, prototipação e apresentação de suas ideias para a criação de soluções tecnológicas que possam melhorar a vida das pessoas em diferentes contextos como educação, sustentabilidade, gênero, saúde, mobilidade urbana. Os estudantes são orientados a realizarem as atividades por acadêmicos dos cursos de Engenharia e TIC.

Os minicursos oferecidos são de diversos temas, entre eles estão computação desplugada, desenvolvimento de aplicativos móveis e jogos digitais, construção de robôs e sistemas de automação, montagem de circuitos elétricos e eletrônicos, implementações e construções da domótica e de cidades inteligentes. Para a realização das tarefas o projeto busca utilizar ferramentas mais dinâmicas e interativas para estimular, explorar a criatividade e a refletir sobre os desdobramentos da tecnologia na vida das pessoas.

\section{Materiais e Métodos}

A oficina foi aplicada no laboratório de informática da Universidade Federal de Santa Catarina, tendo como amostra 20 estudantes do Ensino Médio na faixa etária dos 15 aos 16 anos.

Para a criação do protótipo de cidade inteligente buscou-se utilizar ferramentas tecnológicas interativas, dentre elas estão o uso de kits da LEGO, plataforma de desenvolvimento Arduino, kit de circuitos elétricos Littlebits, para a desenho de peças utilizou-se o software AUTOCAD e para a impressão foi utilizada uma impressora 3D.

No primeiro momento foi aplicado um questionário inicial, contendo perguntas que visavam conhecer as motivações que os levaram a participar do projeto, bem como os conhecimentos acerca dos termos "cidade inteligente", "ciência", e quais as experiências com atividades tecnológicas e utilização do computador, como softwares, que normalmente utilizavam no seu dia a dia.

Quanto ao processo de desenvolvimento da oficina aconteceu em dois momentos, o Primeiro - exposição dos conteúdos teóricos, abordando conceitos bases de cidades inteligentes e IoT e de suas contribuições positivas na vida da sociedade moderna. Além disso, ocorreram demonstrações, por meio de documentários e vídeos, exemplificando algumas aplicações tecnológicas - destacadas na Seção 3 - com o objetivo de despertar o lúdico de forma bastante visual. Na sequência, foram realizadas as apresentações das ferramentas tecnológicas utilizadas para a criação do protótipo de cidade inteligente. O Segundo - a construção prática das aplicações de cidades inteligentes.

Optou-se pela separação em equipe de 5 estudantes, para que assim fosse possível dividir os 20 alunos em quadro grupos, de forma a proporcionar o maior contato possível entre eles na realização da atividade. Só assim seria possível fazer o rodízio de atividades de modo que os quatro grupos estariam trabalhando o tempo todo sob o acompanhamento de um bolsista com cada grupo, e a supervisão do professorsupervisor com todos.

As equipes construíram cada qual seu protótipo, esse por sua vez, deveria estar relacionado a aplicações tecnológicas para automatizar uma residência; promover um 
jogo de golfe; construir um teleférico; e desenvolver um jogo de futebol controlado pelo smartphone.

Casa Inteligente: Desenvolvida com foco em automação residencial, onde o desafio era automatizar alguns itens de uma residência, como: portões, iluminação e controle de presença de pessoas que entravam na casa. A equipe montou uma maquete para simular tal projeto, e a maquete contava com sensores de distância e de água para perceber a presença de pessoas e tomar ações, como acender luzes e abrir portas; e informar a quantidade de chuva, respectivamente. O controle era realizado por meio de um microcontrolador Arduino UNO. (Figura 1).

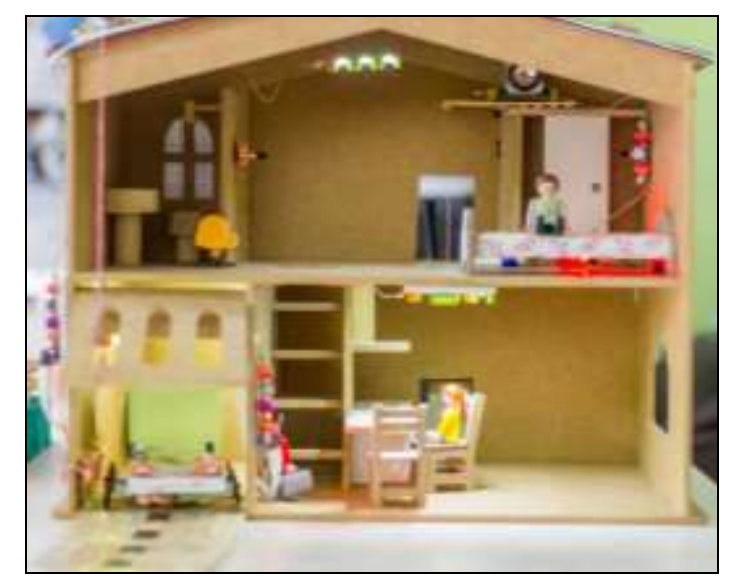

Figura 1 - Casa inteligente desenvolvida nas oficinas.

Jogo de Futebol: O intuito desse projeto era construir e programar dois robôs que simulariam um jogo de futebol. Os jogadores eram controlados através de smartphones utilizando uma comunicação bluetooth do Kit LEGO Mindstorm. (Figura 2).

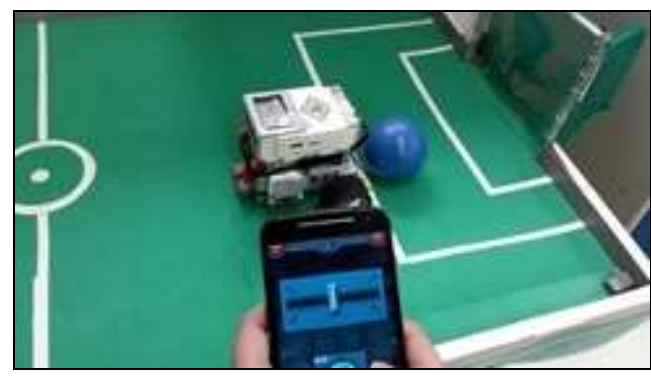

Figura 2 - Jogo de futebol desenvolvido nas oficinas.

Jogo de Golfe: A ideia desse projeto era controlar a força da tacada de um jogador de golfe. Para isso, foi acoplado um servo motor no protótipo do jogador e ajustado o valor da corrente elétrica através de um potenciômetro. (Figura 3). 


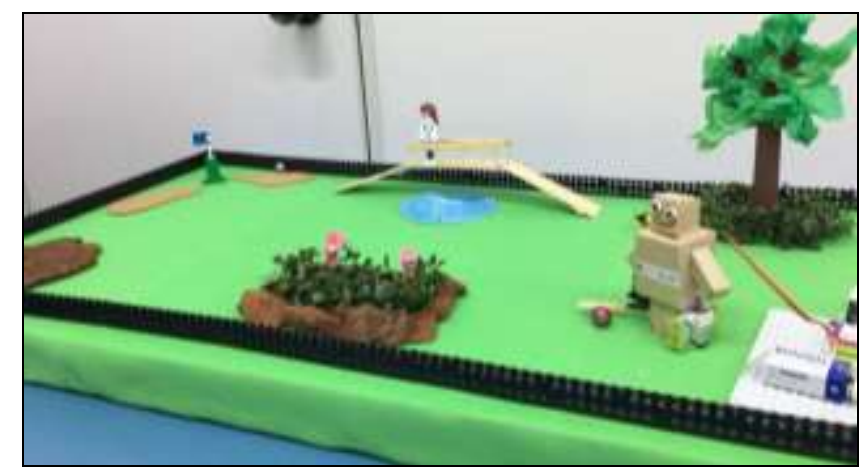

Figura 3 - Jogo de golfe desenvolvido nas oficinas.

Automação de Teleférico: A automação de um teleférico foi desenvolvida com o intuito de apresentar uma aplicação de IoT para controlar os motores de corrente contínua utilizando o Kit Littlebits. Foi possível realizar o controle - sentido de rotação dos motores - do teleférico por meio da conexão sem fio do sistema com um dispositivo móvel. (Figura 4).

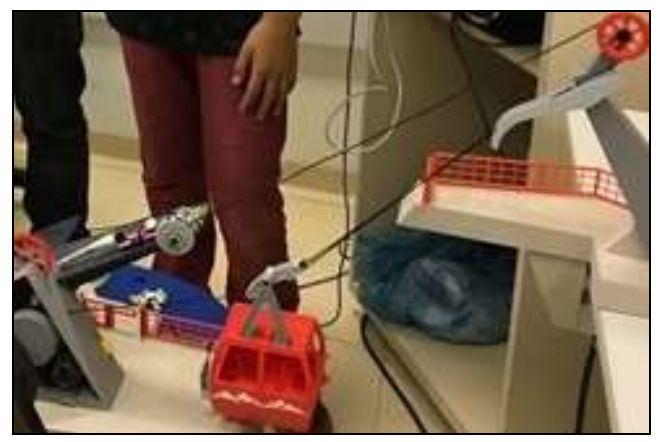

Figura 4 - Automação de teleférico desenvolvida nas oficinas.

Quanto ao segundo questionário, este por sua vez, sobre a análise da atividade prática, foi aplicado com o intuito de observar quais foram as principais dificuldades encontradas ao longo do desenvolvimento da atividade.

A próxima etapa foi elaborada as apresentações da atividade, na qual cada grupo deveria mostrar as funcionalidades das suas construções. Essa interação permitiu um melhor relacionamento dos bolsistas com as estudantes, e assim um melhor rendimento dos alunos na atividade.

Por fim, foi aplicado um questionário final com a propósito de observar a contribuição da implementação das aplicações de cidades inteligentes no ensinoaprendizagem de ciências exatas. 


\section{Resultados e Discussão}

Os resultados dessa pesquisa estão estruturados em subseções: questionário inicial, apresentando as opiniões dos estudantes sobre a perspectiva dos ambientes de tarefas proposto antes da construção da cidade inteligente; questionário de análise da atividade prática, apresentando os resultados dos experimentos práticos realizados por meio dos materiais e métodos propostos; e questionário final.

\subsection{Questionário Inicial}

No início da primeira oficina, os estudantes responderam um questionário solicitando que descrevessem o entendimento sobre alguns conceitos de tecnologia, de computação e de eletrônica. Percebeu-se que a maioria não tinha um entendimento real sobre esses conceitos, respondendo, às vezes, vagamente, ou assumindo não ter ideia do que poderiam ser. Os participantes responderam a seguinte pergunta: "Você já pensou em como as cidades inteligentes são desenvolvidas?". O questionário teve uma amostra de 20 entrevistados: $37 \%$ responderam não ter ideia de como é a construção; $30 \%$ acharam que eram construídas apenas por meio de programação; $26 \%$ acreditam que são sistemas programados por meio de robôs e 7\% acharam que as cidades inteligentes são projetos nos quais se faz o uso de três áreas principais: Internet das Coisas, Big Data e Governança Algorítmica. A (Figura 5) apresenta o gráfico estabelecido sobre a questão discutida.

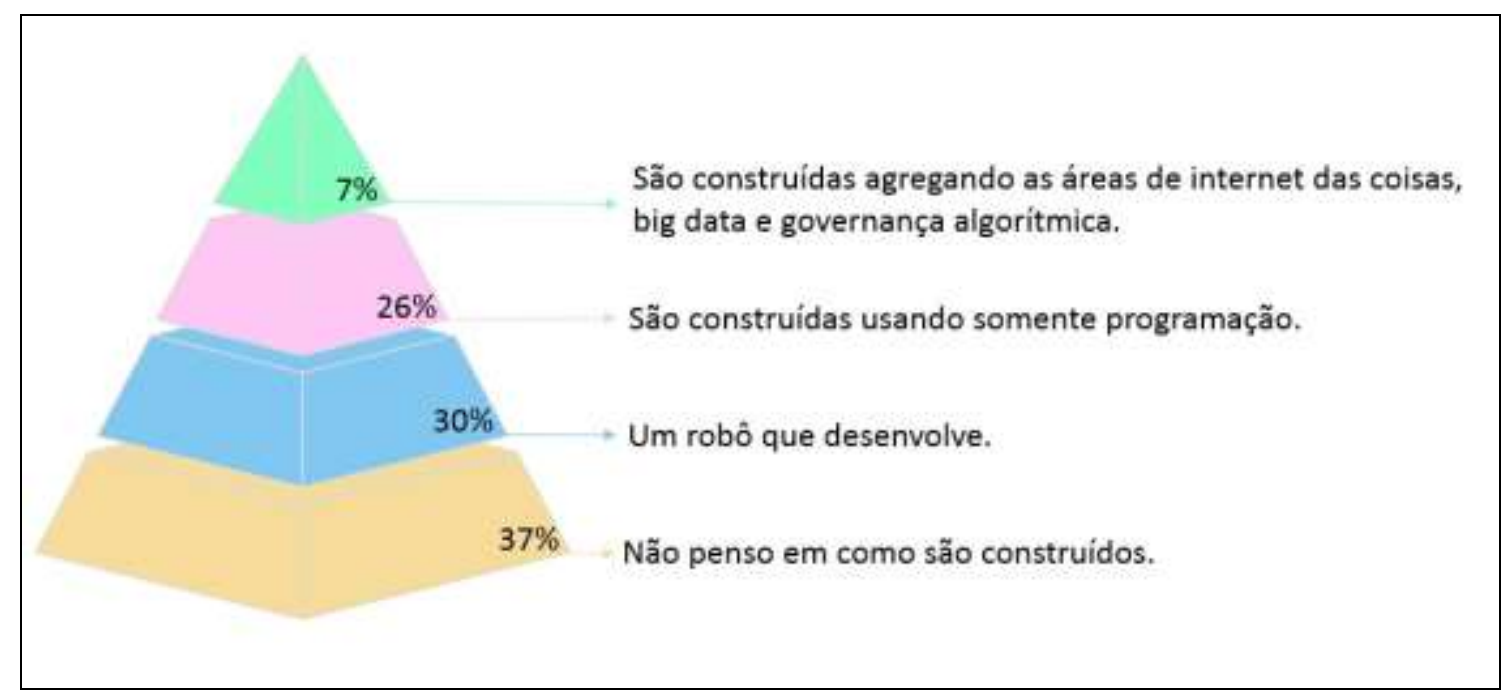

Figura 5 - Gráfico com levantamento de opiniões sobre como as cidades inteligentes são desenvolvidas.

\subsection{Análise da Atividade Prática}

Quanto ao segundo questionário, este por sua vez, sobre a análise da atividade prática, da mesma amostra de entrevistados: $75 \%$ disseram ter encontrado dificuldades com a parte de programação, ou seja, a parte lógica/software; $15 \%$ disseram ter encontrado dificuldades na parte de construção da aplicação, neste caso, a parte física/hardware; por fim, apenas $2 \%$ disseram ter encontrado problemas com as características das ferramentas tecnológicas para realizar a tarefa proposta. 


\subsection{Questionário Final}

O questionário final foi aplicado com a finalidade de observar a contribuição da implementação das aplicações de cidades inteligentes no ensino-aprendizagem das ciências exatas. Um dos questionamentos foi: "Hoje em dia, há muitas oportunidades de se adquirir novos conhecimentos em Ciências Exatas de forma divertida e interativa. Essas oportunidades, muitas vezes, são oferecidas por projetos como o Projeto Meninas Digitais - UFSC. Você acha que essas iniciativas influenciam de maneira positiva os estudantes?". Quanto às respostas da mesma amostra: 73\% disseram achar muito interessante essas iniciativas, pois viabiliza aos participantes adquirirem novos conhecimentos, conhecer novas tecnologias, ampliar a criatividade e que instigam o aprendizado; $11 \%$ disseram achar interessante, pois permitem aos participantes novos conhecimentos; $7 \%$ relataram achar pouco interessante, pois não mostram de maneira efetiva como funciona o ramo da tecnologia na sociedade; por fim, $9 \%$ responderam não achar instigante, afinal, não se interessam pela área das ciências exatas e tecnológicas. A (Figura 6) apresenta o gráfico estabelecido.

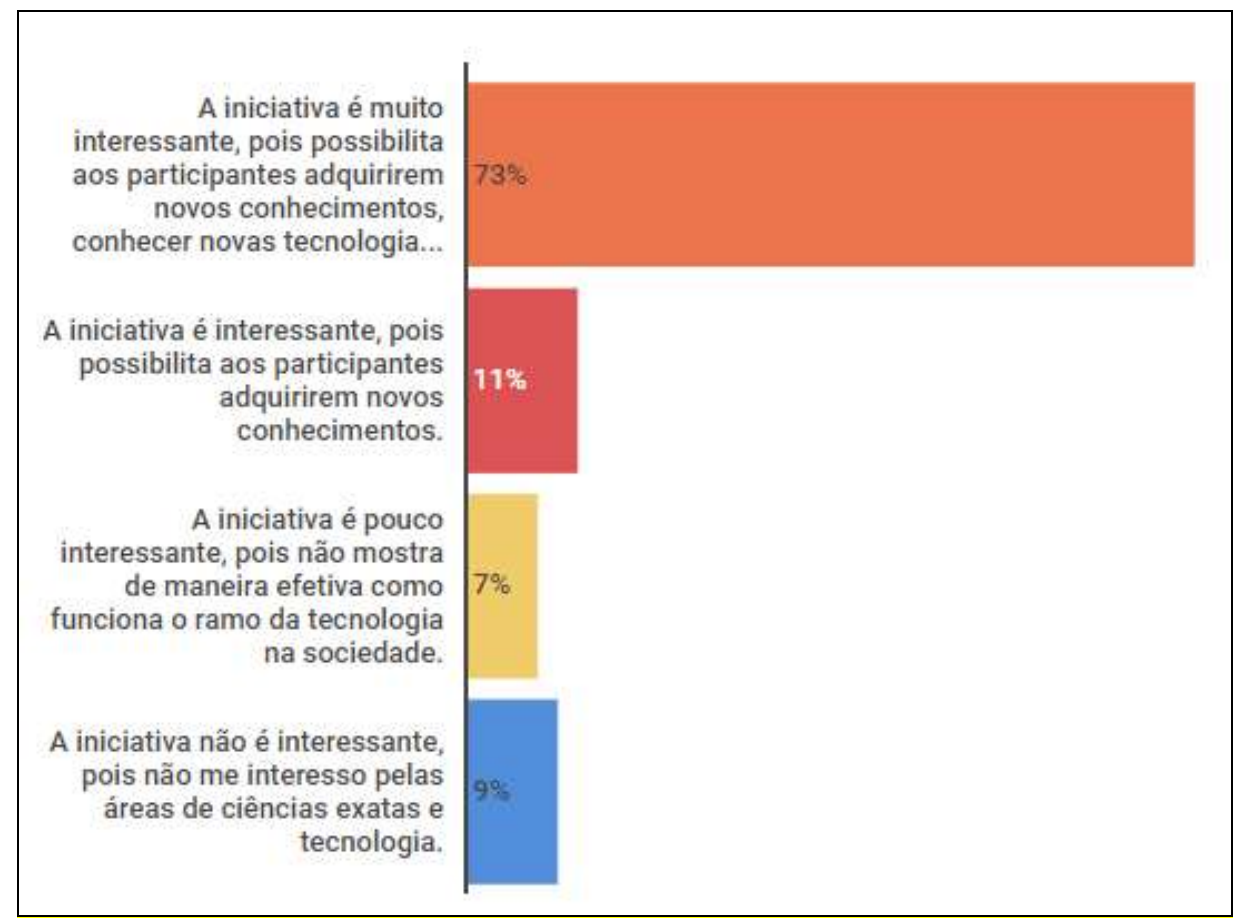

Figura 6 - Gráfico com levantamento de opiniões sobre a iniciativa do Projeto.

Observando as demais respostas do questionário de encerramento, analisou-se maior consistência. Assim, foi possível perceber as mudanças ocorridas no entendimento dos conceitos abordados nas aulas práticas. A aprendizagem também foi percebida através dos comentários e observações que os estudantes realizaram ao final do encontro relatando suas construções, tentativas, erros e acertos. O que nos possibilitou acompanhar o processo de evolução do desenvolvimento dos alunos durante as atividades propostas. 


\section{Considerações Finais}

Partindo dos resultados preliminares da investigação e considerando aqueles provenientes da análise dos questionários aplicados nas oficinas realizadas, os relatos apontam que foi possível proporcionar aos estudantes uma nova forma de visualizar conteúdos interdisciplinares. Outra conclusão que sobressai da análise realizada trata do uso da tecnologia no campo educacional, como forma mais atrativa. Este aspecto nos leva a elencar que a proposta do Projeto traz benefícios para os estudantes, professores, instituições de ensino e toda a comunidade.

Enfatizamos a importância da criação de ambientes educacionais motivadores que proporcionam a possibilidade de aquisição de novas habilidades e competências aos estudantes. A utilização de ferramentas tecnológicas, como suporte no ensino aprendizagem das Ciências Exatas, é fortalecedora da autonomia do estudante e da discussão e reflexão à inserção tecnológica no cotidiano da sociedade contemporânea.

\section{Referências}

ANDERLE, D. F.; JUNIOR, V. F.; GAUTHIER, F. A. O. A Utilização da Tecnologia da Informação nas "Smart Cities" - um Estudo Bibliométrico. In: III CONGRESSO INTERNACIONAL DO CONHECIMENTO E INOVAÇÃO, 2013.

COELHO, M. H.; SARTOR, M.; FRIGO, L. B.; POZZEBON, E. Incentivando o Ingresso de Mulheres em Cursos de Engenharia e Tecnologia. In: XXXVI CONGRESSO DA SOCIEDADE BRASILEIRA DE COMPUTAÇÃO, 2016.

FERREIRA, H. N. M.; ARAÚJO, R. D.; SOUZA, P. C.; JÚNIOR, S. C. S.; DORÇA, F. A.; CATTELAN, R. G. Gamificação em Ambientes Educacionais Ubíquos. In: XXVI SIMPÓSIO BRASILEIRO DE INFORMÁTICA NA EDUCAÇÃO, 2015.

FERNANDEZ, C. O.; BIAZON, L. C.; MARTINAZZO, A. A. G.; FICHEMAN, I. K.; LOPES, R. D. Uma proposta baseada em projetos para oficina de Internet das Coisas com Arduino voltadas a estudantes do Ensino Médio. Revista Novas Tecnologias na Educação, v.13, n. 2, dezembro, 2015.

GAMA, K.; ALVARO, A.; PEIXOTO, E. Em Direção a um Modelo de Maturidade Tecnológica para Cidades Inteligentes. In: VIII SIMPÓSIO BRASILEIRO DE SISTEMAS DE INFORMAÇÃO, 2012.

PEREIRA, G. V. Contribuição de iniciativas de cidades inteligentes no desenvolvimento humano: uma análise da percepção de agentes de centros de operações municipais no Brasil. Tese (Doutor em Administração). Pontifícia Universidade Católica do Rio Grande do Sul - PUCRS, Porto Alegre, 2016.

ROCHA, E. F. AND CASTIGLIONI, M. C. Reflexões sobre recursos tecnológicos: ajudas técnicas, tecnologia assistida, tecnologia de assistência e tecnologia de apoio. Revista de Terapia Ocupacional, São Paulo, v. 16, n. 3, p. 97-104, set/dez. 2005. 